\title{
Are better results from anatomy or surgery?
}

\author{
E. Dean McKenzie, MD
}

See related article on pages 508-13.

The authors present the results of their institutional preference for surgical management of patients with critical aortic stenosis or atresia, arch hypoplasia or interruption, and a well developed left ventricle in the presence of a ventricular septal defect (VSD). A single-stage biventricular repair, the so-called Yasui operation, was performed in 15 patients over a 9-year period, applying the logic that the vulnerable physiology of the shunted, functionally univentricular circulation is avoided. The results are enviable, with an operative mortality of $6.7 \%$, demonstrating that this technically challenging procedure can be carried out safely.

The 3 patients who underwent staged biventricular repair are rightly excluded from the statistical analysis, as they would have been exposed to the disadvantages of a univentricular circulation for an average of 17 months. Eight of the 15 patients had an interrupted aortic arch and VSD, and were judged to have an unusable aortic valve. Although the numeric aortic annular dimensions are not provided, several patients had aortic annular $\mathrm{z}$-scores of -3 or -4 assigned by echo, which means that some of these aortic valves would have accepted a 5-mm dilator. Therefore, some could have been managed with arch reconstruction and VSD closure alone, which is a much less complicated procedure, although it admittedly only postpones aortic valve replacement.

The authors compare the 15 patients who underwent the 1 -stage Yasui procedure with a cohort of 113 patients who underwent a Norwood procedure during the same era.
The outcomes for the Yasui group were superior to those in the Norwood cohort, who experienced an operative mortality of $16 \%$. The diagnoses for those in the Norwood cohort are not reported, but one could assume that the majority had a morphologically univentricular heart. I believe most would agree that a patient with aortic atresia, VSD, and 2 well developed ventricles undergoing a Norwood procedure would have an expected mortality of much less than $16 \%$. The superior results experienced in the Yasui cohort may be more a function of the underlying cardiac diagnosis than the surgical approach.

The Yasui operation is a technically challenging and uncommon procedure, but minimal explanation of the surgical procedure was undertaken in this report. Consideration should be given to the location of the right ventriculotomy. A ventriculotomy that positions the right ventricle to pulmonary artery conduit away from the sternum can make intracardiac exposure for baffle creation quite difficult. At times, a ventriculotomy to the right of the pulmonary valve is preferable, and the conduit may be directed to the right of the neoaorta, making conduit replacement easier.

By report, VSD enlargement was not undertaken, so the high incidence of surgical heart block, 2 of 15, is difficult to explain given the typical outlet extension of the VSD in this morphology. It may be that multiple pacemaker revisions, in addition to the necessary conduit exchanges associated with the biventricular repair, would result in a long-term outcome that is inferior to that of a Fontan circulation in a patient with 2 well developed ventricles.

I congratulate the authors for achieving outstanding results with an uncommon and technically challenging procedure.

\footnotetext{
From the Department of Congenital Heart Surgery, Texas Children's Hospital, Baylor College of Medicine, Houston, Texas.

Disclosures: Author has nothing to disclose with regard to commercial support.

Received for publication Oct 18, 2014; accepted for publication Oct 20, 2014; available ahead of print Nov 21, 2014

Address for reprints: E. Dean McKenzie, MD, Congenital Heart Surgery, Texas Children's Hospital, Baylor College of Medicine, 6621 Fannin St, West Tower, Floor 19, Houston, TX 77030 (E-mail: edmckenz@texaschildrens.org).

J Thorac Cardiovasc Surg 2015;149:514

$0022-5223 / \$ 36.00$

Copyright (c) 2015 by The American Association for Thoracic Surgery

http://dx.doi.org/10.1016/j.jtcvs.2014.10.088
} 